\title{
Sample Representation and Substantive Outcomes Using Web With and Without Incentives Compared to Telephone in an Election Survey
}

\author{
Oliver Lipps ${ }^{1}$ and Nicolas Pekari ${ }^{2}$
}

The objective of this article is to understand how the change of mode from telephone to web affects data quality in terms of sample representation and substantive variable bias. To this end, an experiment, consisting of a web survey with and without a prepaid incentive, was conducted alongside the telephone Swiss election survey. All three designs used identical questionnaires and probability samples drawn from a national register of individuals.

First, our findings show that differences in completion rates mostly reflect different levels of coverage in the two modes. Second, incentives in the web survey strongly increase completion rates of all person groups, with the exception of people without Internet access or limited computer literacy. Third, we find voting behavior to be much closer to official figures in the web with the incentive version compared to the two other designs. However, this is partly due to the different sociodemographic compositions of the samples. Other substantive results suggest that the incentive version includes harder-to-reach respondents. Unit costs are much lower in the two web designs compared to the telephone, including when a relatively high incentive is used. We conclude that in countries with high Internet penetration rates such as Switzerland, web surveys are already likely to be highly competitive.

Key words: Web surveys; mode experiment; incentive effects; individual register frame; national election survey.

\section{Nonobservation and Measurement Issues in Web and Telephone Surveys}

\subsection{Nonobservation and Sample Composition Differences}

In the early 2000s, survey methodologists began studying web surveys as an alternative to traditional survey modes. From the outset, the major concern was the limited Internet access of some groups regarding various demographic variables such as sex and age (Brandtzæg et al. 2011; Zickhur and Smith 2012), education (Struminskaya et al. 2014; Mohorko et al. 2013a), marital status (Struminskaya et al. 2014), and urbanicity (Mohorko et al. 2013a). While in these studies those with Internet at home are more often male, young, highly educated, unmarried, and live in more urbanized areas, Revilla and Saris (2013) for instance find very little difference between the face-to-face European Social Survey (ESS) and the Longitudinal Internet Studies for the Social Sciences (LISS) online

\footnotetext{
${ }^{1}$ Corresponding author: FORS - Swiss Centre of Expertise in the Social Sciences, c/o University of Lausanne Quartier Mouline Lausanne 1015, Lausanne, Switzerland. Email: oliver.lipps@ fors.unil.ch

${ }^{2}$ FORS - Swiss Centre of Expertise in the Social Sciences, c/o University of Lausanne Quartier Mouline Lausanne 1015, Lausanne, Switzerland. Email: nicolas.pekari@fors.unil.ch
} 
panel in the Netherlands. The latter does make a strong effort to improve representativity, including providing a computer with an Internet connection to those who lack one, but it shows the potential for high-quality surveys using the web. The trend of increasing Internet availability, with a penetration rate as high as 86.6\% in Switzerland in 2014 and 82.1\% in Europe 2015 (International Telecommunication Union, http://www.itu.int/en/ ITU-D/Statistics/Pages/stat/default.aspx), will also continue to work in favor of web surveys in terms of an increasingly smaller substantive variable bias, with a smaller bias in more economically developed countries (Mohorko et al. 2013a).

Conversely, in telephone surveys, the increasing landline telephone undercoverage in Europe is causing an increasing bias in both demographic and substantive variables (Mohorko et al. 2013b). For most Western European countries, the number of households without a telephone plays a minor role (Busse and Fuchs 2012). This is due to an increasing proportion of households who have substituted a mobile phone for their landline (Ernst Stähli 2012; Joye et al. 2012; Blumberg and Luke 2013; Link and Fahimi 2008), and those with an unlisted landline number (Von der Lippe et al. 2011). In Switzerland, the Swiss Federal Statistical Office (SFSO) recorded an average matching rate of individuals sampled at random from their individual population register and matched against their own register of landline numbers of around 76\% (Joye 2012). The SFSO does not provide unlisted landline numbers to other organizations.

Those without a landline differ in particular from those with a listed number. People without a landline are younger (Joye et al. 2012; Blumberg and Luke 2013), live in larger municipalities, and are more often unmarried (Von der Lippe et al. 2011; Lipps and Kissau 2012) or of foreign nationality (Cobben and Bethlehem 2005; Lipps and Kissau 2012). In addition, the increasing volume of marketing calls is causing certain groups of potential telephone-survey respondents, especially the more affluent, to employ gatekeeper technologies to screen calls. These issues render the telephone increasingly problematic as a survey tool in terms of achieving a representative sample of a population.

A number of studies have compared web with telephone surveys (Fricker et al. 2005; Braunsberger et al. 2007; Chang and Krosnick 2009; Dillman et al. 2009; Nagelhout et al. 2010; Yeager et al. 2011). However, most of the web surveys considered do not use a probability sample. This is unfortunate as, according to the current state of research, nonprobability web surveys might not be a viable alternative in terms of their representativity (Chang and Krosnick 2009; Baker et al. 2010; Yeager et al. 2011). Because representative lists of e-mail addresses of the general population are not available, most web surveys use a sample drawn from an Random Digital Dialing (RDD)-screened sample (Chang and Krosnick 2009; Yeager et al. 2011) or from online panels (Braunsberger et al. 2007; Baker et al. 2010; Nagelhout et al. 2010). Undercoverage, selection effects and panel conditioning might bias inferences drawn from such samples (Warren and Halpern-Manners 2012), including estimates of population frequencies and percentages, and often remain a neglected problem (Schonlau et al. 2009). Other studies use subsamples with Internet access drawn from an RDD sample, which are then randomly assigned to telephone or web (Fricker et al. 2005). One exception is Atkeson et al. (2014), who compare a probability-based telephone poll and a web poll and find only a few differences between survey modes regarding demographic characteristics. One data source that allows for a comparison of web and telephone respondents, under the premise that face-to-face respondents are representative of the population, is the ESS 2010. Among 
respondents of the ESS 2010, 24\% of Swiss adults never use the Internet and ten percent do not own a landline telephone. Our calculations reveal that older, female, married people, those living in larger households, the Swiss-German-speaking part of Switzerland, or in smaller municipalities are more likely to possess a landline. Internet use is more common among younger individuals, men, or those living in larger households. With respect to substantive variables, controlled for sociodemography, we find a positive correlation between Internet use and both political interest and voting behavior, but no correlation of the latter variables with landline possession.

Unlike undercoverage, differences in nonresponse between the two modes are not directly comparable because this depends strongly both on sample matching effort in the case of the telephone (if the sample was drawn from a source that does not include telephone numbers; for the survey used in this article, see Lipps et al. 2015) and on fieldwork effort. In addition, by optimizing the design for each mode, many factors vary other than the mode of interview (Dillman 2000; 2011). Examples include sample members contacted through different methods, or a difference in the number of calls or the number of reminders, as well as the use of incentives. Despite the difficulties of comparing response rates and respondent compositions across different modes, some authors have attempted this, and there seems to be some agreement in that response rates to probabilitybased web surveys are lower than those for comparable interviewer-based surveys. For example, one meta-analysis finds that web surveys on average yield an $11 \%$ lower response rate compared to other modes (Lozar Manfreda et al. 2008). A more recent example is that of Sinclair et al. (2012), who compare web and telephone in a communitybased epidemiological survey in Melbourne, Australia, and find an Internet response rate of $4.7 \%$ and a telephone response rate of $30.2 \%$. When interpreting these figures, we must bear in mind that response rates are very much dependent on contexts such as the topic, the country, or fieldwork efforts (see e.g., Groves et al. 2004a,b).

Given the issues related to comparing specific effects, we choose to measure a "mode system effect" (Biemer and Lyberg 2003, also Biemer 1988) in order to compare data quality. This means that rather than trying to isolate the effects of mode with respect to the quality indicators we use, we measure effects of the entire data-collection process designed around a specific mode and thus compare whole systems of data collection. We measure the difference between the two systems regarding completion rates, sociodemographic composition, distributions of substantive variables, and the cost of data collection. Note that we abstain from using the term "response rate", because this does not include errors arising from noncoverage. We instead talk of nonobservation or completion rate (Callegaro and DiSogra 2008). In addition, we are able to measure bias regarding sociodemographic and political behavior variables by comparing survey outcomes with official figures.

\subsection{Measurement Effects}

In addition to differences in coverage and nonresponse between phone and web modes, differences also arise because of the mode itself. In particular, interviewer-administered surveys are known to produce more socially desirable answers (Krosnick 1991), whether on the telephone (Kreuter et al. 2008; Chang and Krosnick 2009; Atkeson et al. 2014) or 
face-to-face (De Leeuw 2005). However, these differences can also be attributed in part to selection effects (Chang and Krosnick 2009).

In addition, in visual modes, such as web-administered questionnaires, respondents tend to think in the order in which the response categories are presented and are more likely to choose those presented at the beginning of a list of response alternatives than those at the end (primacy effect). On the contrary, in an aural format, such as telephone, respondents are expected to wait until the interviewer has read all the response categories and are thus more likely to start thinking about the last alternatives read to them (recency effect; e.g., Christian et al. 2008). De Leeuw (2005), Dillman and Christian (2005) and Dillman et al. (2009) note, however, that the evidence found for this so far is not completely consistent.

Regarding the accuracy of reported political behavior and preferences, Stephenson and Crête (2011) find the number of differences in point estimates to be relatively high. Malhotra and Krosnick (2007), comparing web data with the 2000 and the 2004 American National Election Study (ANES) face-to-face surveys, find accuracy to be higher for the face-to-face probability-sample data than for the online-panel sample data in the majority of the comparisons, in particular for voting turnout and party choice. However, more recent research tends to show that high-quality web surveys are comparable to traditional modes. For instance, Ansolabehere and Schaffner (2014) state that with the correct sampling methods and weighting, web surveys can produce point estimates comparable to a telephone survey.

\section{Incentive Effects in Web Surveys}

\subsection{Effects on Response Rates}

In addition to high nonresponse rates, partial completes (Peytchev 2009) may be a concern in web surveys. Different types of incentives are thus often used to mitigate these problems and a number of experiments have been designed to analyze the effects of different types of incentives both for surveys that recruit online and offline. Regarding online recruitment, one meta-analysis of 32 surveys showed that incentives significantly increased the motivation to start a survey, and another meta-analysis of 26 studies found that incentives were effective in motivating participants to finish a web survey (Göritz 2006). In addition, studies using online access panels tend to support the reciprocity norm (Groves et al. 1992), in that prepaid incentives are more effective than conditional incentives in web surveys (Bosnjak 2005; Su et al. 2008). In addition, the economic exchange theory (Ryu et al. 2006) is supported because cash (Birnholtz et al. 2004; van Veen et al. 2011) and larger incentives have been found to be more effective (Schaurer et al. 2012). Both effects can also be found in telephone surveys (Singer et al. 2000; Curtin et al. 2007; Sánchez-Fernández et al. 2010). However, in their study Bosnjak and Tuten (2003) find that prepaid incentives do not increase completion rates.

Only a few studies test incentive effects for samples recruited offline. In the study by Alexander et al. (2008), which recruited sample members by mail, the prepaid incentive had better overall enrollment rates. The rates also slightly increased with greater incentive value although men responded more to the $\$ 2$ bill than either the $\$ 1$ or the $\$ 5$ bill. In an address-based experiment, Messer and Dillman (2011) found that a $\$ 5$ prepaid cash 
incentive was effective at improving both web and mail response rates. Providing an incentive significantly increased web response rates by 17.9 percentage points. Scherpenzeel and Toepoel (2012) also report positive prepaid incentive effects from an offline (via telephone or face-to-face) recruitment for the Dutch LISS panel survey. However, they do not find increased response rates in the 20 Euro and 50 Euro designs compared to those seen at the 10 Euro level. Finally, Parsons and Manierre (2014) report that the use of unconditional incentives improved response rates in a web survey based on a random sample of college students.

In addition to incentives, Messer and Dillman (2011) tested the use of priority mail, which did not improve response rates. However, the inclusion of an additional \$5 incentive in combination with priority mail produced slightly higher response rates, although the differences were not statistically significant.

\subsection{Effects on Sample Composition and Response Quality}

Research on the effects of incentives on sample composition and response quality in web surveys is scarce. Two possible hypotheses are generally advanced: according to the first, the incentive draws respondents who would not have responded otherwise and whose response quality is possibly poorer, and, according to the second, the reward from the incentive leads to an improvement in the quality of answers (Singer and Ye 2013). The results regarding these hypotheses are mixed, and most research has found no significant difference in response quality. Göritz (2004), for instance, reports only small effects. In a meta-analysis, Singer and Bossarte (2006) find that incentives may raise response rates without decreasing the nonresponse bias because they motivate individuals who were already more predisposed to respond. They conclude that "more research is needed on how monetary incentives can reduce nonresponse bias rather than merely raising the rate of response" (413). Parsons and Manierre (2014) in turn find that prepaid cash incentives may actually produce results that are less representative of the target population. In a metastudy, Singer and Ye (2013) report that most studies find no or only small effects on sample compositions and call for additional research on the subject. Regarding the effect of incentives on substantive results, Teisl et al. (2006) find that different incentive conditions yield different responses, even when response rates and demographic compositions are the same, concluding that incentives do draw different kinds of respondents. However, direct effects of incentives on response distributions have not been found (Singer and Ye 2013).

Although this literature review reports some inconsistent findings, we are able to draw several preliminary conclusions:

- With respect to sample composition, respondents to web surveys tend to be younger, male, better educated, unmarried, and live in more urbanized areas. Conversely, respondents to landline surveys tend to be older, less educated, natives, and living in less urban areas.

- Studies that compare differences in substantive variables in interviewer-based and web mode are scarce. Most studies use the face-to-face mode as the interviewerbased survey mode. There is a tendency for face-to-face surveys to achieve more accurate results. 
- While unconditional cash incentives are able to increase response rates in web surveys, the effect on the sample composition and on substantive answers is unclear. However, the majority of studies uses samples of special population groups (e.g., students), RDD-screened samples, or online panels.

In our view, the biggest issue with existing studies is that most mode comparisons, including web surveys, are based on nonprobability samples or reference surveys (usually face-to-face) that are biased by nonresponse. In addition, RDD-screened samples suffer from undercoverage problems. As for substantive variables, comparisons using interviewer-based surveys as the reference point are undermined by the fact that these may suffer from a high social-desirability bias. Studies using random samples are rare and there is a lack of information about unobserved sample members.

In this article, we approach the issues above by comparing a telephone survey with a web survey, both based on a probability sample. We use three designs with a randomized mode and incentive, all using the same questionnaire. The web survey includes a prepaid cash-like incentive experiment. We address sampling shortcomings in past research by using three samples that were drawn at random from an individual population register maintained by the SFSO. This register has the added advantage of containing the sociodemographic variables of age, sex, marital status, municipality size, and language region for all sample members.

We analyze completion rates and sample composition in the three designs (telephone, web without incentive, web with incentive). In addition, we compare voting behavior (turnout and party choice) with the actual election results in all three designs and finally discuss cost issues.

\section{Data and Experimental Design}

The Swiss quadrennial election survey Selects (http://www.selects.ch) set up a web experiment alongside the regular CATI survey in the context of the 2011 survey. The samples for all three designs were randomly drawn from the national individual register. The CATI sample was stratified by the 26 Swiss cantons (NUTS 3 level) with small cantons oversampled to a minimum of 100 respondents each $(\mathrm{N}=8,162$ adult citizens). The sample was matched against different telephone registers with a matching rate of $85 \%$. The field period ran from October 24 (the day after the election) to November 25, 2011. No incentives were offered to CATI sample members. For the web survey, 1,481 additional Swiss citizens were selected in a simple random sample design from the national individual register and recruited offline.

All sample members received an advance letter with the university letterhead and signed by the director of the project. The basic content of all letters was the same: a description of the study, including its purpose and why it is important that the person responds, the length of the interview, which was estimated at around 30 minutes for both modes, and contact information in case of questions. The only difference between the letters in the two modes was that in one the modalities of the telephone interview were explained, whereas for the web sample, the individuals were asked to complete the survey online using the Selects 2011 URL (www.selects2011.ch) and a unique code. No special Internet equipment was provided in the context of the study. Web-sample members unable to access the Internet 
therefore had no possibility of taking the survey. Therefore, while the telephone-sample members were told that they would be called by an interviewer in the coming days, the websample members were expected to be proactive by accessing the questionnaire online.

In order to compensate for this difference, 485 of the 1,481 web-sample members received a $20 \mathrm{CHF}(\mathrm{CHF}=.82 €=1.11 \$$ (as of February 52014$)$ ) (prepaid) postal check with the advance letter, whereas 996 did not receive this incentive. Postal checks can be cashed at no cost at any post office in Switzerland. The wording of the letters for the two web-sample members was identical except for the additional paragraph explaining the incentive to those who received one. In both web designs, two reminders were sent to those who had not yet responded within an identical timeframe. The announcement letters were sent on Friday October 21 by regular mail so that they would be received on Monday October 24 or Tuesday October 25 , and the reminder letters were sent by priority mail on Friday November 4 and Wednesday November 16, ensuring that they would be received on the following day. This was done to minimize the number of individuals completing the interview in the meantime and thus receiving a reminder even though they had already completed the survey. Standard mail was used for the advance letter because for logistical reasons it was not possible to send the letters from the university on a Saturday, and with priority mail many would already have received the letter on the Saturday before the elections. Priority mail was also the preferred method for conveying the reminders as some individuals might think a letter sent by standard mail was an advertisement. The final respondents included in the data responded on December 12.

The telephone and the web questionnaire were the same, with only slight changes made to the wording of the questions to adapt them to a written mode. Each telephone-sample member was called at different times and refusal conversions attempted using more experienced interviewers. We summarize the contact dates and materials sent for each mode in Table 1.

\section{Completion Rates and Sample Composition}

In this chapter, we analyze response rates (RR1; AAPOR 2011) in the three designs for the sample members distinguished by experimental design and the variables available from the sampling frame. Unlike in the telephone mode, a general problem of the web mode is that the two components of noncompletion (or nonobservation) - noncoverage and nonresponse - cannot be separated. For a discussion of undercoverage and nonresponse issues in the telephone survey used here, see Lipps et al. (2015). In a web survey, noncompletion can only be further analyzed in the case of a break off, in which the sample member was at least found and successfully contacted, but did not complete the survey. For clarity, we consider incomplete responses as nonresponses. Note that incomplete surveys play a minor role in the web designs since only 14 sample members $(1.4 \%)$ broke off the questionnaire in the without-incentive design and nine sample members (1.9\%) in the with-incentive design. For both telephone and web, people without access to the contact mode are deemed "noncompleters". Total and group-specific completion rates (in proportions), as well as significance levels measured as $\mathrm{chi}^{2}$-differences between completers and noncompleters across the three designs are presented in Table 2.

Telephone has only a slightly higher (6\% points) overall completion rate than web without incentive. Individuals who are older than 56 years, married, women, and 


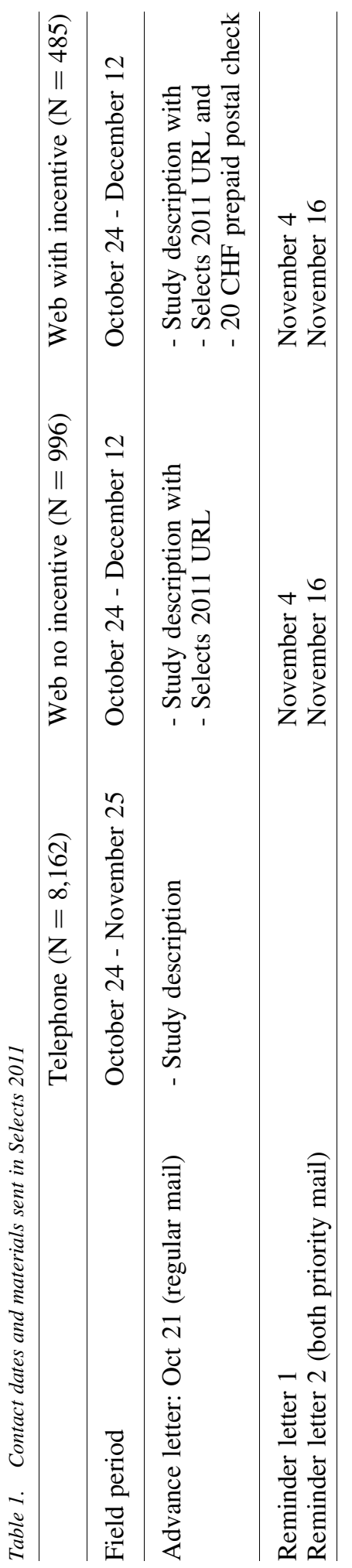




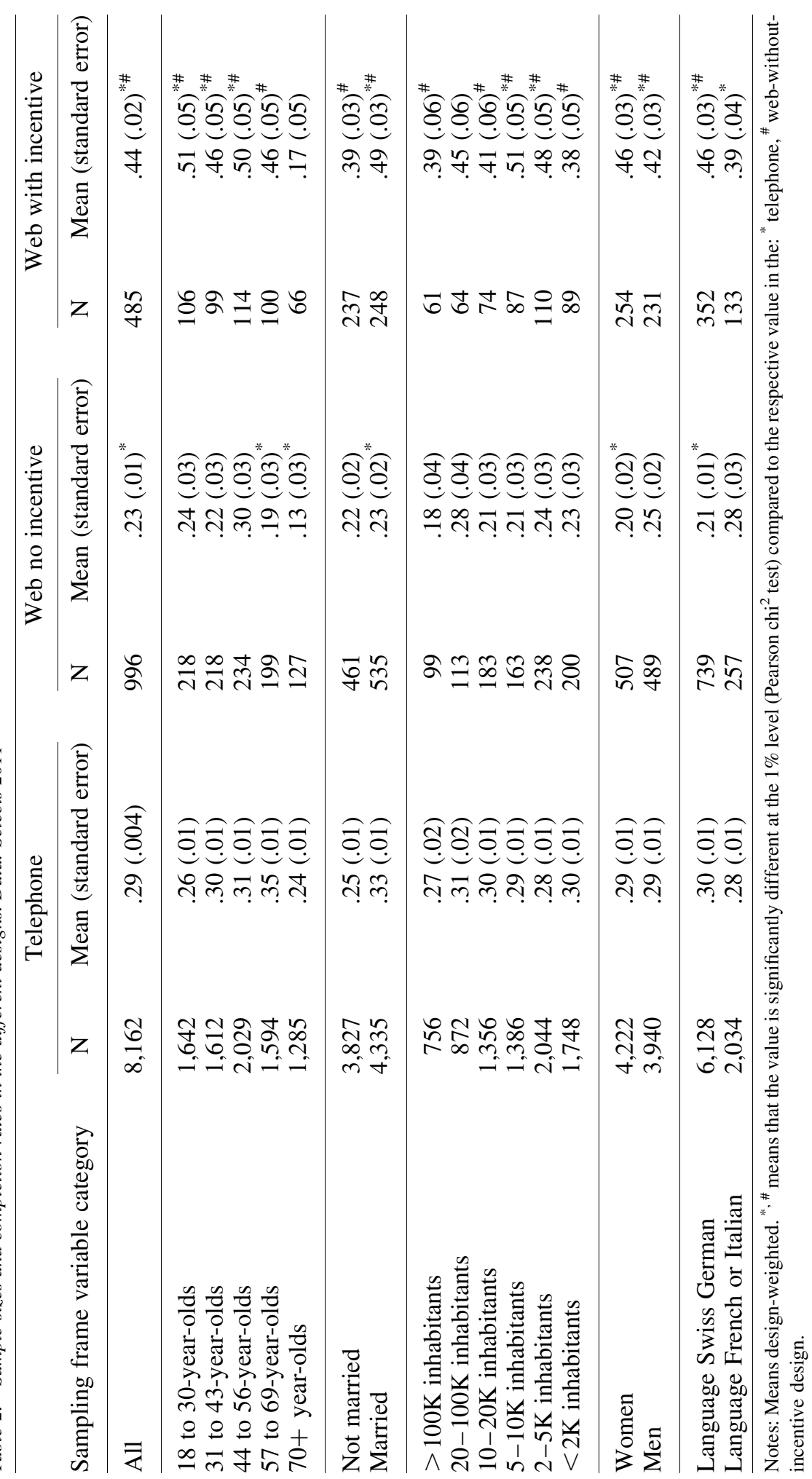


Swiss-German speakers respond significantly ( $5 \%$ level) less in the web design. Comparing the two web designs, the incentive increases completion rates for all groups (21\% points overall), and most comparisons are statistically significant except for the $70+$ group.

In Table 3 we examine sample composition in the population, the total sample, and the three designs. Compared to census data, young people, those in smaller villages, and Swiss-German speakers are slightly overrepresented in the total sample. Comparing the total sample with the respondents in the three designs, individuals who are young, unmarried, from large municipalities ( $>100 \mathrm{~K}$ inhabitants), and who speak French or Italian are underrepresented among the telephone respondents, and older individuals are underrepresented among the web respondents. The relative underrepresentation of older people becomes worse with the incentive. Although the composition of the web-withincentive sample is quite different to that of the web-without-incentive sample, no group of persons is significantly different due to the small sample sizes. Because the chi $^{2}$-values are not comparable between the designs, we analyze sample bias of the three designs using the sum of the absolute percentage differences to the total sample across all 17 categories of the five sociodemographic variables. The maximum absolute percentage difference would be 500 percentage points if the samples were distributed completely differently across the five variables (e.g., in the case of sex, the sample in one design has $100 \%$ women, whereas the total sample has $100 \%$ men, and similarly for the other four variables). This method gives percentage point differences of 40.9 in the telephone design, 61.0 in the web-without-incentive design, and 49.8 in the web-with-incentive design across all categories. The telephone sample has the smallest representation bias for age, sex, and municipality size, the web-without-incentive sample has the smallest representation bias for marital status, and the web-with-incentive sample has the smallest representation bias for language group.

The group-specific completion differences and sample composition mostly reflect differential access to landline telephone or web (and its use), respectively (Alexander et al. 2008). On the one hand, compared with the average telephone matching rate $(85 \%)$ of sample members from the individual register, the underrepresented person groups (see Table 3), the 18- to 30-year-olds (74\%), the unmarried (79\%), those in large municipalities $(>100,000$ inhabitants, $77 \%)$, and French $(83 \%)$ or Italian $(81 \%)$ speakers, are less likely to be matched. The 57 to 69 -year-olds, who are overrepresented in the telephone sample, have a telephone matching rate of $92 \%$. For people aged 70 or over, noncooperation is much higher than for other age groups, which is the reason why this age group is still underrepresented among the telephone respondents, in spite of its above-average matching rate $(95 \%)$.

According to the SFSO's Omnibus (2010) survey, 78\% of the population over 15 uses the Internet (at least once during the last three months), but the figure is much lower for older groups: $45 \%$ for those aged 65 to 74 and only $20 \%$ for those aged $75+$. In our results, there is a reverse effect of telephone and Internet coverage: people with higher telephone coverage (older, Swiss-German speakers) tend to have lower Internet coverage and vice versa. Exceptions are married people who have both high telephone and high Internet coverage, probably due to economies of scale in larger households. For those with less web access (and lower computer literacy) such as older people, even an incentive is not able to substantially increase participation. 


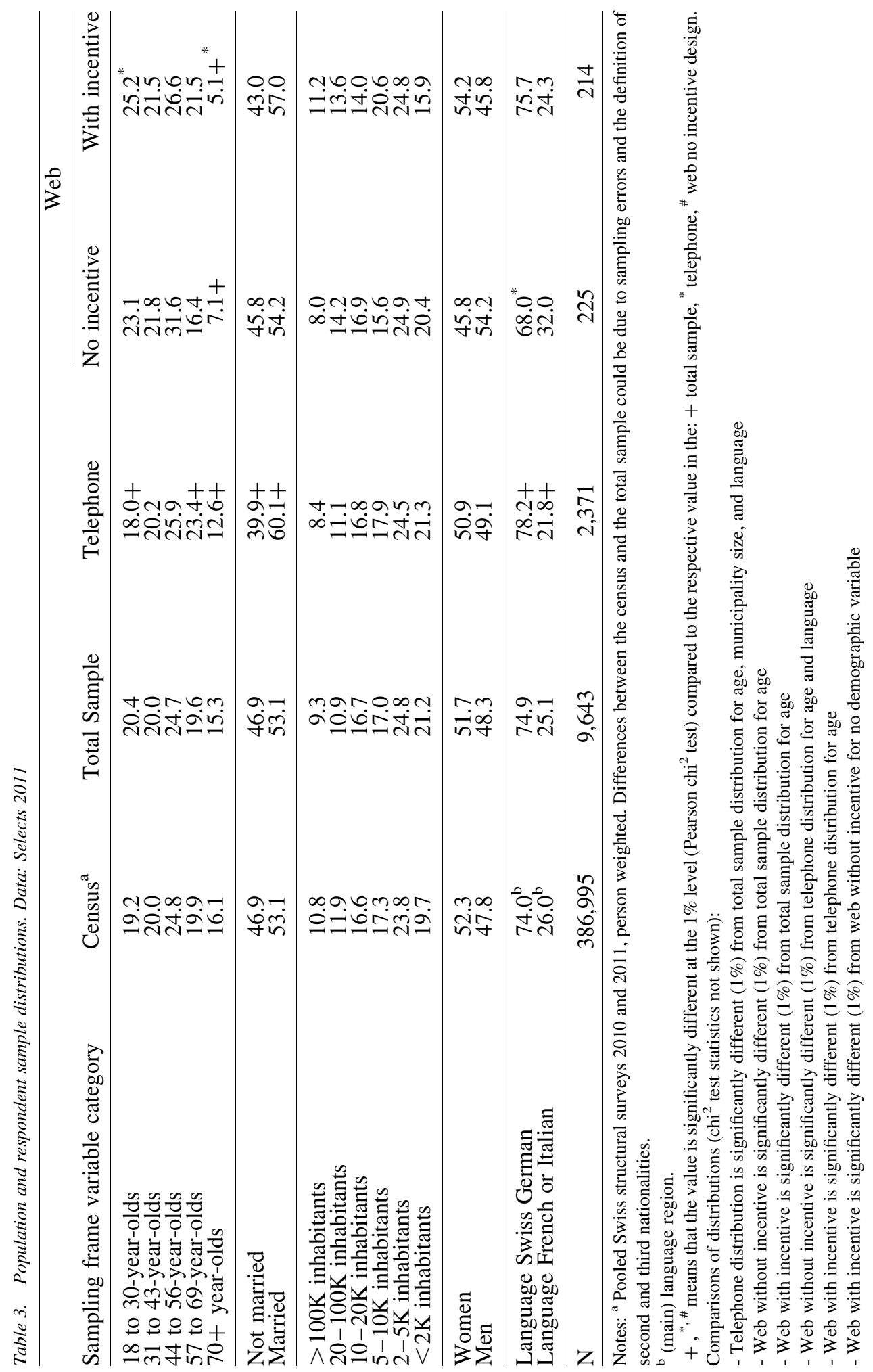




\section{Substantive Results}

We analyze some key variables regarding political behavior, without and with sociodemographic control variables. The variables included in the models are: age group, gender, education, marital status, language region, municipality type, and religion. As already seen, the composition of the samples varies between designs. We wish to know whether the differences in substantive variables are due to this variation or whether there are other sources of variation, such as mode effects. We prefer sociodemographic control variables to weighting because the variables which the weights are based on can be included in the regression models easily, avoiding possible errors that can arise from creating weights (see e.g., Little and Vartivarian 2003). To control for sociodemographic variables, we use logistic regressions (Poisson regression for the two likert scale variables of political interest and participation) with the design as the sole independent variable in the first part of the table and in conjunction with the sociodemographic variables in the second. The predicted marginal values were calculated so as to compare coefficients across different models (Mood 2010).

Generally, we note that due to the small sample sizes in the web designs, the number of significant differences between the two web designs is very small, even though differences in absolute terms are large for many comparisons.

A particular strength of the Selects survey is that questions about political behavior are asked within a short timeframe immediately following the elections. This makes it possible to compare turnout and party choice with the official results, see Table 4. It is known that election surveys tend to overestimate turnout, due both to overreporting (social desirability) and selection bias (Burden 2000; Holbrook and Krosnick 2010; Karp and Brockington 2005; McDonald 2003; Selb and Munzert 2013). In our study, it appears that the web-with-incentive design is more accurate, where the result of $65.7 \%$ is eight percentage points closer to the actual figure of $48.5 \%$ compared to the telephone survey. Without incentive, the result of the web survey is very similar to that of the telephone survey. It would appear that in this case selection bias is probably a stronger reason for the differences than overreporting, as the main change occurs when an incentive is added and not between modes.

To analyze vote choice, a left/center/right variable was constructed. This combination is necessary due to the large number of parties in Switzerland and the ensuing low number of cases by party in the web conditions, especially after excluding non-voters. In Table 4, we find the distribution to be much closer to the actual election results for the web-withincentive design. The change is particularly apparent in the case of right-wing parties, whose voters are strongly underrepresented in the two other conditions.

Individuals who are more interested and active in politics are generally easier to reach in surveys (see e.g., Groves et al. 2004a,b). In the web-without-incentive design, people appear to be more interested in politics and vote more often, while the opposite is true when an incentive is offered. The incentive thus seems essential if we wish to attenuate the bias towards those who are interested and active in politics in a web survey.

Even though the differences are not significant between the telephone and the web-withincentive samples, there is a consistent tendency towards less politically interested individuals in the latter. We thus hypothesize that this design is also able to reach people 


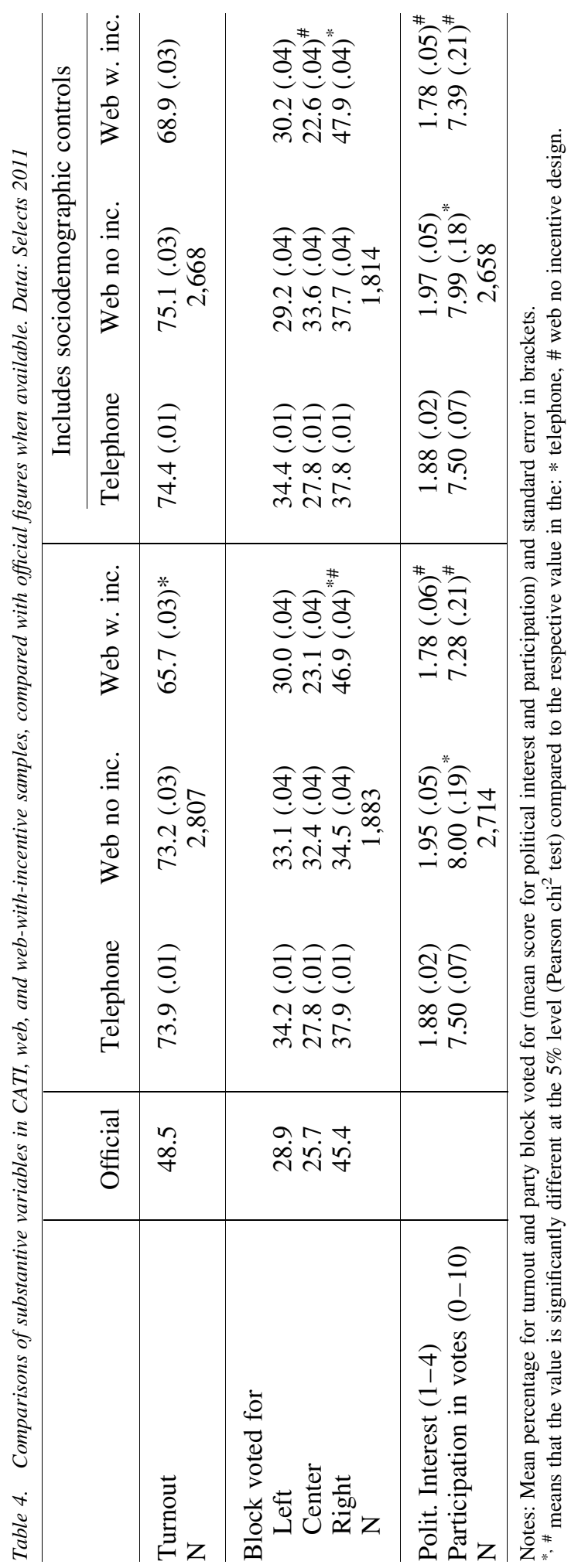


who would not respond to the traditional telephone survey. This is consistent with the inclusion of more right-wing voters. Our results show that the web-with-incentive design has certain advantages in obtaining a more representative sample of the studied population regarding political behavior.

We then turn to the results of the predicted probabilities for turnout and vote choice after controlling for sociodemographics in the right panel of Table 4. We find some changes compared to the uncontrolled figures. For instance, turnout figures become larger for the web design, in particular with incentive. This shows that some of the initial difference between web and telephone is due to the inclusion of sociodemographic groups who vote less in the web (with incentive). Regarding voting behavior, the numbers change slightly for the telephone. For the web modes, the tendency is that the difference between support for the right and the left increases in favor of the right, especially in the design without incentive. In addition, the difference in support for center parties becomes significant as the changes go in opposite directions. It would appear that while the web mode attracts fewer individuals with the sociodemographic characteristics of voters in general, and right-wing voters in particular (e.g., individuals from rural areas), the incentive is powerful in attracting right-wing voters. In turn, sociodemographic groups linked with voting for the left (e.g., individuals from urban areas) are overrepresented in the nonincentivized web survey. Some of the differences regarding voting behavior between the three conditions can thus be explained simply by the different sociodemographic composition of the net samples. However, we find this to be only a very small part of the explanation, and it does seem that the incentive, and to a lesser extent the mode, attracts individuals who are different regarding their political preferences and behavior, net of their sociodemographic profile. Finally, we tested primacy and recency effects in the two modes considered elsewhere (Lipps and Pekari 2013) and found them to be insignificant.

\section{Cost Issues}

As the final part of our comparison of modes, we briefly present the cost by mode. For the results to be more generalizable, we include two cost estimates for the web survey: the costs of the actual in-house survey and the cost if the survey had been done by a survey company. The costs are estimated based on two offers received during the call for tenders for the Selects 2011 project. The in-house web survey was carried out by the Selects team, consisting of a project leader, a junior researcher, a doctoral student, and students for the administrative tasks. The centralized CATI survey was outsourced to a survey company. The figures provide an indication of the cost savings that can be achieved by switching from telephone to web survey. In Table 5, we present a summary of the survey costs by design, assuming a targeted number of 2,000 respondents in each design. Costs for the incentivized version of the web are listed in brackets.

As can be expected, the web-without-incentive design is by far the cheapest mode, followed by web with incentive. Unit costs amount to about $23 \mathrm{CHF}$ in the web-withoutincentive survey, to $43 \mathrm{CHF}$ in the web-with-incentive survey (both in house), and to 94 $\mathrm{CHF}$ in the telephone survey. If the web survey had been carried out by a survey company, the costs would have been $38 \mathrm{CHF}$ without incentive, and $58 \mathrm{CHF}$ with incentive. Interestingly, the incentive design cost only an additional $4 \mathrm{CHF}$ per sample member, 
Table 5. Calculated unit costs for the Selects 2011 survey (in CHF), assuming a targeted number of 2,000 respondents in each design. Figures in brackets are for the incentive condition. Data: Selects 2011

\begin{tabular}{lcrr}
\hline Cost Component & Telephone & Web In House & Web Survey Firm \\
\hline CATI total (survey firm) & $94 .-$ & & \\
$\begin{array}{l}\text { Web total (survey firm) } \\
\text { Programming and project } \\
\quad \text { management web }\end{array}$ & & 38.- (30.-) \\
$\begin{array}{l}\text { Postage web (incl. reminders) } \\
\text { Coding open questions web }\end{array}$ & & & \\
Incentives web & & $15 .-(7 .-)$ & \\
Total & $94 .-$ & $\left(28 .-^{-}\right)$ & $\left(28 . .^{\#}\right)$ \\
\hline
\end{tabular}

"Note: For a nominal value of $20 \mathrm{CHF}$, an uncashed postal check costs $3.5 \mathrm{CHF}$, a cashed postal check costs 23.5 CHF. $83 \%$ of the respondents cashed the check; of the nonrespondents, $13 \%$ cashed it. Given a response rate of $44 \%$, the incentive per sample member costs $.44 *(.83 * 23.5+.17 * 3.5)+.56 *(.13 * 23.5+.87 * 3.5)=12.3$ which makes $12.3 / .44=28.0$ per respondent.

although its nominal value amounts to $20 \mathrm{CHF}$, plus a $3.50 \mathrm{CHF}$ administrative charge. Primarily, this is due to the fact that only a part of the sample members actually cash the check. Sending the same amount of cash would cost 20/.44 $=45.5$ CHF per respondent. Ceteris paribus, the cost savings amount to $45.5-28.0=17.5$. CHF. Secondly, as much as $8 \mathrm{CHF}$ per sample member can be saved due to the almost twice as high response rate by sending much fewer letters (announcement and reminder) in the web-with-incentive condition. Whether this holds true for other surveys in other contexts needs further examination. Absolute cost figures will depend very much on the survey and cultural context, but we believe the cost structures to be roughly comparable in relative terms.

\section{Summary of Findings}

We find that completion rates in the telephone survey are only slightly higher than those in the web-without-incentive design, but considerably higher in the web-with-incentive design. Switching from telephone to web without incentive reduces completion rates for people who are 57 years and older, married, women, or Swiss-German speakers. The incentivized web survey increases participation almost across the board. The main concern with using the web design are those aged 70 and above, who are simply likely to be unable to complete the survey independent of their willingness to do so, whether for lack of an Internet connection or for the lack of the necessary computer literacy.

When calculated as the absolute percentage differences to the census, sample composition bias is highest in the web-without-incentive design, followed by the webwith-incentive design, and finally the telephone. While in both web designs older people are underrepresented, married people and Swiss-German speakers are overrepresented in the telephone design, and young people in both web designs, especially in the incentivized version. Swiss-German speakers are underrepresented in the web-without-incentive design.

As for substantive outcomes, the web-with-incentive design comes closest to the official voting results in terms of turnout and party choice. In addition, the mean values for political interest and voting participation, typically overestimated in election surveys, are 
lower than those for the other two designs. In contrast, telephone and web without incentive overestimate turnout and underestimate voting for right-wing parties. Sociodemographic controls lead to some changes, but do not explain the differences found between the different conditions.

Finally, the web survey costs much less, even with a $20 \mathrm{CHF}$ incentive. A rough comparison between the three designs results in unit costs that are about four times as high in the telephone design compared to the web-without-incentive design (provided the web survey is conducted in house). Incentives increase the costs by about a sixth.

\section{Conclusion}

In the present study, we analyze the effects of two different modes (telephone and web) and a randomized incentive experiment within the Swiss Electoral Study (Selects) 2011 survey. The aim of this study is to analyze the effects of a possible switch from telephone to web due to cost and landline undercoverage issues. The innovation of our research is that we use a probability sample in each design. We focus on mode system effects (Biemer and Lyberg 2003). That is, we are interested in the systematic effects that are largely independent of (unavoidable) sampling and fieldwork-related differences. We examine completion rates and sample composition in the three designs distinguished by the frame variable characteristics. We then analyze substantive results and finally compare unit costs in the three designs.

The web-with-incentive design outperforms the web-without-incentive design not just in terms of response rates but also in regard to sample composition and substantive outcomes at comparatively small additional cost. It also outperforms the telephone mode on all accounts, except for a small disadvantage in terms of sample composition. In addition, the unit costs of the web-with-incentive survey are less than a half of that of the telephone survey. An incentivized web survey thus already appears to be highly competitive compared to the telephone survey in the context of an election study.

Compared to a survey of the general population, our findings must be seen as relating to the special case of an election survey. First, we only sample adults, and second, foreigners are excluded from the sample. Therefore, problems such as language, literacy, and - last but not least - motivation to complete the survey are likely to play a smaller role in our sample of adult Swiss citizens. Second, we are able to make use of an address register which allows individualized invitation letters to be sent to the sample members. Limitations include the comparatively small web-sample sizes, which make it difficult to compare distributions or sample statistics with the larger telephone survey. In addition, one would wish to have a full factorial design experiment, including a telephone-withincentive design, to better evaluate the incentive effect in both modes. An important finding is that, while controlling for sociodemographics when comparing substantive results shows some sample selection tendencies, it is not able to explain selection effects related to other personal characteristics unrelated to sociodemographics (values, attitudes, etc.), which are likely to constitute the lion's share of the effects. Finally, we are unable to uncover whether substantive differences across the designs result from selection or mode (measurement) effects. We believe that fully identifying these effects is an important issue for further research (see, e.g., Vannieuwenhuyze and Loosveldt 2013). Nevertheless, 
we are confident that we have been able to demonstrate the strong potential of web surveys, compared with traditional telephone surveys, in an environment where technological and societal trends clearly speak in favor of this mode.

\section{References}

AAPOR (The American Association for Public Opinion Research). 2011. Standard definitions: Final dispositions of case codes and outcome rates for surveys, 7 th ed. AAPOR.

Alexander, G., G. Divine, M. Couper, J. McClure, M. Stopponi, K. Fortman, D. Tolsma, V. Strecher, and C. Johnson. 2008. "Effect of Incentives and Mailing Features on Online Health Program Enrolment." American Journal of Preventive Medicine 34: 382-388. Doi: http://dx.doi.org/10.1016/j.amepre.2008.01.028.

Ansolabehere, S. and B. Schaffner. 2014. "Does Survey Mode Still Matter? Findings From a 2010 Multi-Mode Comparison.” Political Analysis 22: 285-303. Doi: http://dx.doi. org/10.1093/pan/mpt025.

Atkeson, L., A. Adams, and R. Alvarez. 2014. "Nonresponse and Mode Effects in Self-and Interviewer-Administered Surveys." Political Analysis 22: 304-320. Doi: http://dx.doi. org/10.1093/pan/mpt049.

Baker, R., S.J. Blumberg, J.M. Brick, M.P. Couper, M. Courtright, J.M. Dennis, D. Dillman, M.R. Frankel, P. Garland, R.M. Groves, C. Kennedy, J. Krosnick, P.J. Lavrakas, S. Lee, M. Link, L. Piekarski, K. Rao, R.K. Thomas, and D. Zahs. 2010. "Research Synthesis AAPOR Report on Online Panels." Public Opinion Quarterly 74: 711-781. Doi: http://dx.doi.org/10.1093/poq/nfq048.

Biemer, P. 1988. "Measuring Data Quality.” In Telephone Survey Methodology, edited by W. Nicholls II, R. Groves, P. Biemer, L. Lyberg, J. Massey, W. Nicholls II, and J. Waksberg, 273-283. New York: Wiley \& Sons.

Biemer, P. and L. Lyberg. 2003. Introduction to Survey Quality. New York: John Wiley \& Sons.

Birnholtz, J., D. Horn, T. Finholt, and S. Bae. 2004. "The Effects of Cash, Electronic, and Paper Gift Certificates as Respondent Incentives for a Web-Based Survey of Technologically Sophisticated Respondents." Social Science Computer Review 22: 355-362. Doi: http://dx.doi.org/10.1177/0894439304263147.

Blumberg, S. and J. Luke. 2013. Wireless Substitution: Early Release of Estimates from the National Health Interview Survey. July-December 2012. Available at: http://www. cdc.gov/nchs/data/nhis/earlyrelease/wireless201306.pdf (accessed December 2014).

Bosnjak, M. 2005. "Effects of Two Innovative Techniques to Apply Incentives in Online Access Panels." Presentation at the General Online Research Conference (GOR), Zürich, March 22-23.

Bosnjak, M. and T. Tuten. 2003. "Prepaid and Promised Incentives in Web Surveys: an Experiment.” Social Science Computer Review 21: 208-217. Doi: http://dx.doi.org/10. 1177/0894439303021002006.

Brandtzæg, P., J. Heim, and A. Karahasanovic. 2011. "Understanding the New Digital Divide - A Typology of Internet Users in Europe.” International Journal of HumanComputer Studies 69: 123-138. Doi: http://dx.doi.org/10.1016/j.ijhcs.2010.11.004. 
Braunsberger, K., H. Wybenga, and R. Gates. 2007. "A Comparison of Reliability Between Telephone and Web-Based Surveys." Journal of Business Research 60: 758-764. Doi: http://dx.doi.org/10.1016/j.jbusres.2007.02.015.

Burden, B.C. 2000. "Voter Turnout and the National Election Studies." Political Analysis 8: 389-398.

Busse, B. and M. Fuchs. 2012. "The Components of Landline Telephone Survey Coverage Bias. The Relative Importance of No-Phone and Mobile-Only Populations." Quality and Quantity 46: 1209-1225. Doi: http://dx.doi.org/10.1007/s11135-011-9431-3.

Callegaro, M. and C. DiSogra. 2008. "Computing Response Metrics for Online Panels." Public Opinion Quarterly 72: 1008-1032. Doi: http/dx.doi.org/10.1093/poq/nfn065.

Chang, L. and J. Krosnick. 2009. "National Surveys via RDD Telephone Interviewing Versus the Internet.” Public Opinion Quarterly 73: 641-678. Doi: http://dx.doi.org/10. 1086/346010.

Christian, L., D. Dillman, and J. Smith. 2008. "The Effects of Mode and Format on Answers to Scalar Questions in Telephone and Web Surveys." In Advances in Telephone Surveys, edited by J.M. Lepkowski, 250-275. New York: Wiley \& Sons.

Cobben, F. and J. Bethlehem. 2005. "Adjusting Undercoverage and Nonresponse Bias in Telephone Surveys.” Discussion paper 05006. CBS, Statistics Netherlands, Voorburg/ Heerlen. Available at: http://www.cbs.nl/nr/rdonlyres/7fd00f42-15a3-4151-9daa-2d54566cf59a/0/200506x10pub.pdf (accessed February, 2016).

Curtin, R., E. Singer, and S. Presser. 2007. "Incentives in Random Digit Dial Telephone Surveys: a Replication and Extension.” Journal of Official Statistics 23: 91-105.

De Leeuw, E. 2005. “To Mix or Not To Mix Data Collection Modes in Surveys.” Journal of Official Statistics 21: 233-255.

Dillman, D. 2000. Mail and Telephone Surveys: The Tailored Design Method. New York: John Wiley \& Sons.

Dillman, D. 2011. Mail and Internet surveys: The Tailored Design Method - 2007 Update With New Internet, Visual, and Mixed-Mode Guide. New York: John Wiley \& Sons.

Dillman, D. and L. Christian. 2005. "Survey Mode as a Source of Instability in Responses Across Surveys." Field Methods 17: 30-52. Doi: http://dx.doi.org/10.1177/ $1525822 X 04269550$.

Dillman, D., G. Phelps, R. Tortora, K. Swift, J. Kohrell, J. Berck, and B. Messer. 2009. "Response Rate and Measurement Differences in Mixed-Mode Surveys Using Mail, Telephone, Interactive Voice Response (IVR) and the Internet." Social Science Research 28: 1-18. Doi: http://dx.doi.org/10.1016/j.ssresearch.2008.03.00.

Ernst Stähli, M. 2012. "Telephone Surveys in Switzerland: Spotlight." In Telephone Surveys in Europe: Research and Practice, edited by M. Häder, S. Häder and M. Kühne, 25-36. Berlin: Springer.

Fricker, S., M. Galesic, R. Tourangeau, and T. Yan. 2005. “An Experimental Comparison of Web and Telephone Surveys." Public Opinion Quarterly 69: 370-392. Doi: http:// dx.doi.org/10.1093/poq/nfi027.

Göritz, A. 2004. "The Impact of Material Incentives on Response Quantity, Response Quality, Sample Composition, Survey Outcome, and Cost in Online Access Panels." International Journal of Market Research 46: 327-345. 
Göritz, A. 2006. "Incentives in Web Studies: Methodological Issues and a Review." International Journal of Internet Science 1: 58-70.

Groves, R., R. Cialdini, and M. Couper. 1992. "Understanding the Decision to Participate in a Survey." Public Opinion Quarterly 56: 475-493. Doi: http://dx.doi.org/10.1086/ 269338.

Groves, R., F. Fowler, M. Couper, J. Lepkowski, E. Singer, and R. Tourangeau. 2004a. Survey Methodology, Wiley Series in Survey Methodology. New York: Wiley.

Groves, R., S. Presser, and S. Dipko. 2004b. "The Role of Topic Interest in Survey Participation Decisions." Public Opinion Quarterly 68: 2-31. Doi: http://dx.doi.org/10. 1093/poq/nfh002.

Holbrook, A.L. and J.A. Krosnick. 2010. "Social Desirability Bias in Voter Turnout Reports Tests Using the Item Count Technique.” Public Opinion Quarterly 74: 37-67. Doi: http://dx.doi.org/10.1093/poq/nfp065.

Joye, C. 2012. "Srph-Castem.” FORS - SFSO workshop, June 21. Neuchâtel.

Joye, D., A. Pollien, M. Sapin, and M. Ernst Stähli. 2012. "Who Can Be Contacted by Phone? Lessons from Switzerland." In Telephone Surveys in Europe: Research and Practice, edited by M. Häder, S. Häder and M. Kühne, 85-102. Berlin: SpringerVerlag.

Karp, J.A. and D. Brockington. 2005. "Social Desirability and Response Validity: A Comparative Analysis of Overreporting Voter Turnout in Five Countries." The Journal of Politics 67: 825-840. Doi: http://dx.doi.org/10.1111/j.1468-2508.2005.00341.x.

Kreuter, F., S. Presser, and R. Tourangeau. 2008. "Social Desirability Bias in CATI, IVR, and Web Surveys.” Public Opinion Quarterly 72: 847-865. Doi: http://dx.doi.org/10. 1093/poq/nfn063.

Krosnick, J. 1991. "Response Strategies for Coping With the Cognitive Demands of Attitude Measures in Surveys." Applied Cognitive Psychology 5: 213-236. Doi: http:// dx.doi.org/10.1002/acp. 2350050305.

Link, M. and M. Fahimi. 2008. "Telephone Survey Sampling." In Sampling of Populations: Methods and Applications, edited by P.S. Levy and S. Lemeshow, 455-487. New York: Wiley.

Lipps, O. and K. Kissau. 2012. "Nonresponse in an Individual Register Sample Telephone Survey in Lucerne (Switzerland)." In Telephone Surveys in Europe: Research and Practice, edited by M. Häder, S. Häder and M. Kühne, 187-208. Berlin: Springer-Verlag.

Lipps, O. and N. Pekari. 2013. Mode and Incentive Effects in an Individual Register Frame Based Swiss Election Study. FORS Working Paper Series, paper 2013-3. Lausanne: FORS.

Lipps, O., N. Pekari, and C. Roberts. 2015. "Coverage and Nonresponse Errors in an Individual Register Frame Based Swiss Telephone Election Study." Survey Research Methods 9: 71-82.

Little, R.J. and S. Vartivarian. 2003. "On Weighting the Rates in Non-Response Weights." Statistics in Medicine 22: 1589-1599. Doi: http://dx.doi.org/10.1002/sim.1513.

Lozar Manfreda, K., M. Bosnjak, J. Berzelak, I. Haas, and V. Vehovar. 2008. "Web Surveys Versus Other Survey Modes: a Meta-Analysis Comparing Response Rates." International Journal of Market Research 50: 79-104. 
Malhotra, N. and J. Krosnick. 2007. "The Effect of Survey Mode and Sampling on Inferences About Political Attitudes and Behavior: Comparing the 2000 and 2004 ANES to Internet Surveys With Nonprobability Samples." Political Analysis 15: 286-323. Doi: http://dx.doi.org/10.1093/pan/mpm003.

McDonald, M.P. 2003. "On the Overreport Bias of the National Election Study Turnout Rate.” Political Analysis 11: 180-186. Doi: http://dx.doi.org/10.1093/pan/mpg006.

Messer, B.L. and D.A. Dillman. 2011. "Surveying the General Public Over the Internet Using Address-Based Sampling and Mail Contact Procedures." Public Opinion Quarterly 75: 429-457. Doi: http://dx.doi.org/10.1093/poq/nfr021.

Mohorko, A., E. de Leeuw, and J. Hox. 2013a. "Internet Coverage and Coverage Bias in Europe: Developments Across Countries and Over Time." Journal of Official Statistics 29: 609-622. Doi: http://dx.doi.org/10.2478/jos-2013-0042.

Mohorko, A., E. de Leeuw, and J. Hox. 2013b. "Coverage Bias in European Telephone Surveys: Developments of Landline and Mobile Phone Coverage Across Countries and Over Time." Survey Methods: Insights from the Field. Doi: http://dx.doi.org/10.13094/ SMIF-2013-00002.

Mood, C. 2010. "Logistic Regression: Why We Cannot Do What We Think We Can Do, and What We Can Do About It." European Sociological Review 26: 67-82. Doi: http:// dx.doi.org/10.1093/esr/jcp006.

Nagelhout, G., M. Willemsen, M. Thompson, G. Fong, B. van den Putte, and H. de Vries. 2010. "Is Web Interviewing a Good Alternative to Telephone Interviewing? Findings from the International Tobacco Control (ITC) Netherlands Survey." BMC Public Health 10: 351. Doi: http://dx.doi.org/10.1186/1471-2458-10-351.

Omnibus 2010. Survey on Information and Communication Technology, Swiss Federal Statistical Office 2010. Excel result sheets (in German; accessed October 21, 2013). Available at: http://www.bfs.admin.ch/bfs/portal/de/index/themen/16/04/data.html (accessed December 2014).

Parsons, N. and M. Manierre. 2014. "Investigating the Relationship Among Prepaid Token Incentives, Response Rates, and Nonresponse Bias in a Web Survey." Field Methods 26: 191-204. Doi: http://dx.doi.org/10.1177/1525822X13500120.

Peytchev, A. 2009. "Survey Breakoff." Public Opinion Quarterly 73: 74-97. Doi: http:// dx.doi.org/10.1093/poq/nfp014.

Revilla, M.A. and W.E. Saris. 2013. "A Comparison of the Quality of Questions in a Face-to-Face and a Web Survey." International Journal of Public Opinion Research 25: 242-253. Doi: http://dx.doi.org/10.1093/ijpor/eds007.

Ryu, E., M. Couper, and R. Marans. 2006. "Survey Incentives: Cash vs. In-Kind, Face-toFace vs. Mail, Response Rate vs. Nonresponse Error.” International Journal of Public Opinion Research 18: 89-106. Doi: http://dx.doi.org/10.1093/ijpor/edh089.

Sánchez-Fernández, J., F. Muñoz-Leiva, F.J. Montoro-Ríos, and J. Ángel Ibáñez-Zapata. 2010. "An Analysis of the Effect of Pre-Incentives and Post-Incentives Based on Draws on Response to Web Surveys." Quality and Quantity 44: 357-373. Doi: http://dx.doi. org/10.1007/s11135-008-9197-4.

Schaurer, I., B. Struminskaya, L. Kaczmirek, and W. Bandilla. 2012. "The Price We Have to Pay: Incentive Experiments in the Recruitment Process for a Probability-Based 
Online Panel." Presentation at the General Online Research Conference (GOR) March 5-7, 2012, Mannheim.

Scherpenzeel, A. and V. Toepoel. 2012. "Recruiting a Probability Sample for an Online Panel. Effects of Contact Mode, Incentives, and Information." Public Opinion Quarterly 76: 470-490. Doi: http://dx.doi.org/10.1093/poq/nfs037.

Schonlau, M., A. van Soest, A. Kapteyn, and M. Couper. 2009. "Selection Bias in Web Surveys and the Use of Propensity Scores." Sociological Methods and Research 37: 291-318. Doi: http://dx.doi.org/10.1177/0049124108327128.

Selb, P. and S. Munzert. 2013. "Voter Overrepresentation, Vote Misreporting, and Turnout Bias in Postelection Surveys." Electoral Studies 32: 186-196. Doi: http://dx. doi.org/10.1016/j.electstud.2012.11.004.

Sinclair, M., J. O’Toole, M. Malawaraarachchi, and K. Leder. 2012. "Comparison of Response Rates and Cost-Effectiveness for a Community-Based Survey: Postal, Internet and Telephone Modes with Generic or Personalised Recruitment Approaches." BMC Medical Research Methodology 12: 132. Doi: http://dx.doi.org/10.1186/ 1471-2288-12-132.

Singer, E. and R. Bossarte. 2006. "Incentives for Survey Participation. When are they 'Coercive'?” American Journal of Preventive Medicine 31: 411-418. Doi: http://dx. doi.org/10.1016/j.amepre.2006.07.013.

Singer, E. J. van Hoewyk, and M. Maher. 2000. "Experiments with Incentives in Telephone Surveys.” Public Opinion Quarterly 64: 171-188. Doi: http://dx.doi.org/10. 1086/317761.

Singer, E. and C. Ye. 2013. "The Use and Effects of Incentives in Surveys." The ANNALS of the American Academy of Political and Social Science 645: 112-141. Doi: http://dx. doi.org/10.1177/0002716212458082.

Stephenson, L. and J. Crête. 2011. "Studying Political Behavior: A Comparison of Internet and Telephone Surveys." International Journal of Public Opinion Research 23: 24-55. Doi: http://dx.doi.org/10.1093/ijpor/edq025.

Struminskaya, B., L. Kaczmirek, I. Schaurer, and W. Bandilla. 2014. "Assessing Representativeness of a German Probability-Based Panel." In Online Panel Research: A Data Quality Perspective, edited by M. Callegaro, R. Baker, J. Bethlehem, A. Göritz, J. Krosnick, and P. Lavrakas, 61-85. New York: John Wiley \& Sons.

Su, J., P. Shao, and J. Fang. 2008. "Effect of Incentives on Web-Based Surveys." Tsinghua Science and Technology 13: 344-347. Doi: http://dx.doi.org/10.1016/ S1007-0214(08)70055-5.

Teisl, M., B. Roe, and M. Vayda. 2006. "Incentive Effects on Response Rates, Data Quality, and Survey Administration Costs.” International Journal of Public Opinion Research 18: 364-373. Doi: http://dx.doi.org/10.1093/ijpor/edh106.

Vannieuwenhuyze, J. and G. Loosveldt. 2013. "Evaluating Relative Mode Effects in Mixed-Mode Surveys: Three Methods to Disentangle Selection and Measurement Effects." Sociological Methods \& Research 42: 82-104. Doi: http://dx.doi.org/10. 1177/0049124112464868.

Van Veen, F., A. Göritz, and S. Sattler. 2011. "The Impact of Monetary Incentives on Completion and Data Quality in Online Surveys." Presentation at the European Survey 
Research Association (ESRA) Conference, Lausanne, July 18-22 and General Online Research (GOR) Conference, Düsseldorf, March 14-16.

Von der Lippe, E., P. Schmich, and C. Lange. 2011. "Advance Letters as a Way of Reducing Non-Response in a National Health Telephone Survey: Differences Between Listed and Unlisted Numbers." Survey Research Methods 5: 103-116. Doi: http://dx. doi.org/10.18148/srm/2011.v5i3.4657\#sthash.qLueRYqS.dpuf.

Warren, J. and A. Halpern-Manners. 2012. "Panel Conditioning in Longitudinal Social Science Surveys." Sociological Methods and Research 41: 491-534. Doi: http://dx.doi. org/10.1177/0049124112460374.

Yeager, D., J. Krosnick, L. Chang, H. Javitz, M. Levendusky, A. Simpser, and R. Wang. 2011. "Comparing the Accuracy of RDD Telephone Surveys and Internet Surveys Conducted with Probability and Non-Probability Samples." Public Opinion Quarterly 75: 709-747. Doi: http://dx.doi.org/10.1093/poq/nfr020.

Zickhur, K. and A. Smith. 2012. Digital Differences. Pew Internet \& American Life Project 13. Available at: http://www.pewinternet.org/2012/04/13/digital-differences/ (accessed August 2014).

Received February 2014

Revised March 2015

Accepted April 2015 